\title{
Correlation Between Family Functioning and Caregiver Burden among Family Caregivers of Patients with Breast Cancer
}

\section{Marisya Putri Andina ${ }^{\mathrm{a}}$ and Lifina Dewi Pohan ${ }^{\mathrm{b}}$}

${ }^{a}$ Faculty of Psychology, Universitas Indonesia, Depok, Indonesia; ${ }^{b}$ Department of Clinical Psychology, Faculty of Psychology, Universitas Indonesia, Depok, Indonesia

*Corresponding author:

Lifina Dewi Pohan

Department of Clinical Psychology

Faculty of Psychology, Universitas Indonesia

Jl. Lkr. Kampus Raya, Depok, Jawa Barat

Indonesia, 16424

Tel.: +62 217270004

Email address: lifina.dewi@ui.ac.id 


\title{
Correlation Between Family Functioning and Caregiver Burden among Family Caregivers of Patients with Breast Cancer
}

\begin{abstract}
Breast cancer is the most common chronic disease among Indonesian women. During treatment, patients require assistance with carrying out daily activities. Family members, as the basic unit, usually become caregivers for patients with breast cancer. As a caregiver, a family member must sometimes manage various problems, in particular, family functioning (Wozniak \& Izycki, 2014). In addition, the changing or multiple roles the family member plays affect the caregiver burden for family caregivers. The purpose of this study is to investigate the correlation between family functioning and caregiver burden among family caregivers of patients with breast cancer who have been caregiving for at least 3 months. Family functioning is assessed using the Family Assessment Device (FAD) with (Epstein, Bishop, \& Levin, 1978), and caregiver burden is assessed using the Zarit Interview Scale (ZBI) (Zarit, Reever, \& Bach-Peterson, 1980). In this study, 35 participants are family caregivers for patients with breast cancer. This study found a significant negative correlation between family functioning and caregiver burden. That is, the higher FAD score, the lower ZBI score issued by a family caregiver of patients with breast cancer.
\end{abstract}

Keywords: family functioning, caregiver burden, family caregivers

\section{Introduction}

Family is an inherent aspect of the human experience. A family unit comprises family members, such as a father, mother, and child, or individuals residing in a household who interact with each other and aspire to achieve common goals (Efendi, 2009). Over time, family members cannot be separated from their roles in the completion of tasks, and they must manage various situations. When managing family situations, family functioning has a critical role for each family member, and family functioning can result in a positive or negative impact. The positive impact is shown in how the family functions, for example, how a family manages a chronic disease diagnosis, and plays a role in determining caregiving for the sick family member (Efendi, 2009). Caregiving from a family member will create support and can have a positive effect on the recovery of patients. Furthermore, Efendi (2009) asserted that the well-being of family members influenced the quality of life of other family members. This assertion was supported by Friedman, Baer, Nelson, Lane, Smith, and Dworkin (1988) who say that family is the main factor in adjusting patients with chronic diseases.

One chronic disease is cancer. Cancer is the fourth leading cause of death in Indonesia. The Department Kesehatan Republik Indonesia (2015) predicted that, in Indonesia, there would be approximately 240,000 new cases of cancer per year, and 70\% of cases would be incurable (Effendy, Vernooij-Dassen, Setiyarini, Kristanti, Tejawinata, Vissers, \& Engels, 2015). According to the World Health Organization (WHO; 2015), the most common cancer in women is breast cancer, and breast cancer is one of the most commonly diagnosed types of cancer in Indonesia (depkes.go.id, 2016). 
A family is negatively affected after learning about a family member's cancer diagnosis. Nissen, Trevino, Lange and Prigerson (2016) observed a relationship between family functioning and psychosocial dysfunction in families with a member who is a cancer patient. In a family, cancer is typically a new experience for family members, and diagnosed patients must manage various problems while undergoing treatment (Wozniak \& Izycki, 2014). One problem is the level of fear patients with cancer experience, and management of this fear is helped by support from family members (Friedman, Baer, Nelson, Lane, Smith, \& Dworkin, 1988). Notably, patients with cancer and their other family members feel emotional reactions, such as anger and feelings of disagreement with the cancer diagnosis, after the initial diagnosis.

In Indonesia, families are a key element in caring for sick family members, at home and while undergoing hospitalization, and this tradition is considered an obligation. By contrast with Western countries, people in Indonesia generally have close family ties and tend to involve themselves in caring for sick family members. Thus, family members have a role as family caregivers in providing caregiving to patients with breast cancer. Individuals who become family caregivers, for example, close relatives such as spouses, children, stepchildren, or other relatives, have family ties with patients (Wozniak \& Izycki, 2014).

Caregiving can be performed by men and women. Women, compared with men, often dominate the role of being a family caregiver (Waliser, Spriggs, \& Feldman, 2002). This phenomenon shows that caregiving and household affairs are a tradition usually conducted by women. When families manage the aspects of a cancer diagnosis, a woman who becomes a family caregiver, compared with a man, has more means to manage the problems experienced (Kershaw, Northouse, Kritpracha, Schafenacker, \& Mood, 2004). However, Nijboer, Tempelaar, Sanderman, Triemstra, Spruijt, and Van Den Bos (1998) asserted that men, compared with women, who became a family caregiver experienced a lower psychological distress effect. Notably, it cannot be determined with certainty whether women or men have more severe pressure when caregiving for patients with breast cancer.

In a family, cancer causes changes in family identity, daily roles, and functions (Blanchard, Albrecht, \& Ruckdeschel, 1997). As a result, the role dynamics in the family also change, such that the family caregiver has a dual role in the family. Therefore, we suspect that these changes result in an imbalance in the family's family functioning. Family functioning regards all aspects of the family that have the purpose of maintaining or fulfilling all aspects of development owned by other family members (Epstein et al., 1978). In the process of achieving the goals, family functioning has six dimensions: role, communication, problemsolving, affective response, affective involvement, and behavioral control. According to Wozniak and Izycki (2014), families managing the cancer diagnosis of a family member experienced an effect on family functioning. First, cancer can make the model of family interaction change: A cancer diagnosis can cause an excessive burden on one family member because of an excessive role. Second, cancer is an unpredictable disease and results in family members being forced to change or delay their future personal plans and prioritize the patients' needs. The effect of delaying plans for the future can disrupt the stability of family 
functioning, and families may feel they have no future. Third, cancer causes changes in family functioning in external groups, such as offices, schools, or social life, as well as in other groups, such as doctors or nurses.

Disruption of family functioning affects the psychosocial well-being of the patient and the family members. Dorros, Card, Segrin \& Badger (2010) asserted that diagnosis and treatment in patients with breast cancer cause pressure on the patients that affects family well-being, such as causing emotional stress. In addition, stress as a result of a cancer diagnosis affects patients and family caregivers (Weitzner, McMillan, \& Jacobsen, 1999). These problems are a challenge in the caregiving process and have a negative impact on the ability to provide optimal patient care (Fujinami, Sun, Zachariah, Uman, Grant, \& Ferrell, 2015). In patients who receive a diagnosis when the cancer is in an advanced stage, a substantial influence was observed on the psychosocial conditions of patients and their families (Schuler, Zaider, Hichenberg, Masterson, \& Kissane, 2014). This finding was supported by Nissen et al., (2016), who described a relationship between family functioning and psychosocial dysfunction. Nissen et al., (2016) also suggested that being a poorly functioning family caring for a patient with cancer has been associated with an increased risk of depression and anxiety.

One example in the literature of a family caring for a patient with breast cancer observed the following. M was a husband who cared for his wife who was a patient diagnosed with Stage 3 breast cancer. $\mathrm{M}$ said that when his wife was undergoing cancer treatment in a hospital, she tended to be quiet, and $\mathrm{M}$ said his wife was often angry when $\mathrm{M}$ attempted to advise his wife. M's wife felt that $\mathrm{M}$ would not understand her as a patient with breast cancer. Triggered by his wife's feelings, M eventually felt unable to complain to his wife about the problems he had to manage as a result of the cancer diagnosis, such as boredom and financial problems.

Based on these findings, the behavior of patients illustrates that communication in families with members who are patients with breast cancer can be ineffective and cause communication disruption, which is one dimension of family functioning. This finding is in accordance with Wozniak and Izycki (2014), who asserted that a cancer diagnosis makes communication between a husband and wife who are initially fine disturbed because either the husband or wife chooses to not convey his or her condition as a whole. In addition, the disruption of communication is the difference in communication needs, coping strategies, and participants' ability to express emotions (Wozniak \& Izycki, 2014). In addition to the problems observed in couples, the family caregivers of patients with breast cancer have reported problems, for example, with communication and emotional distress (Kershaw, Northouse, Kritpracha, Schafenacker, \& Mood, 2004).

Additionally, when providing care for patients with breast cancer, family caregivers must possess complex skills, for example, planning, decision-making, problem-solving, access to health system resources, and health care system negotiations (Given, Given, \& Sherwood, 2012). Some of these skills can be performed by family caregivers who have high family functioning values in several dimensions. For example, when a person has a high score on the dimension of problem-solving, she or he has one skill to provide care for patients with breast 
cancer. Therefore, the authors feel that a family caregiver with low family functioning affects the poor caregiving to patients with breast cancer.

The performance of caregiving duties for patients with breast cancer is required throughout the treatment process, and possibly until the patient dies. As a result, family caregivers spend almost every minute of every day-24 hours a day and 7 days a week - treating their patients. Nijboer et al. (1998) asserted that providing long-term caregiving to patients with cancer was associated negative effect on health that increases the psychological and physical burdens of the family caregiver.

Caregiving has been proven to be a factor in the emergence of caregiver burden and in its journey tend to increase the prevalence of caregiver burden in the future (Arai, Hosokawa, Washio, Miura, \& Hisamichi, 1997; Goldstein, Concato, Fried, \& Kas1, 2004). Research on the pressure in the caregiving process conducted by a family caregiver was also studied in Indonesia by Ginayarahmah (2013), and the results demonstrated that pressure was higher on a family caregiver compared with a formal caregiver. An explanation for this result was asserted by another example in the literature: The family is a major component of palliative care and is a source of emotional support (Kim, Kim, Kim, Kim, Shin, Shim, Hwang, Chung, \& Yoon, 2016).

Caregiver burdens have been associated with reducing physical and psychological health conditions (Cassileth, Lusk, Brown, \& Cross, 1986; Grunfeld, Coyle, Whelan, Clinch, Reyno, Earle, Willan, Viola, Coristine, Janz, \& Glossop, 2004). The burden on a family caregiver of a cancer patient, and especially on a family caregiver of a breast cancer patient, is a critical predictor of stress and depression. Grunfeld et al., (2004) demonstrated that the physical and emotional stress experienced by patients with breast cancer is a factor that predicts the emergence of distress in the family caregiver. In addition, the caregiver burden undertaken by the family caregiver caring for a breast cancer patient is the strongest predictor of depression and anxiety.

Similar to Grunfeld et al., (2004), the longitudinal study conducted by Nijboer et al., (1998) demonstrated an increase in the psychological and physical burdens in caregivers for patients with cancer, which led to research that attempted to understand the predicting factors. poor adjustments to caregiving activities. The process of caregiving for patients with cancer can worsen because of pressure, resulting in symptoms such as anxiety, depression, despair, fear, and perceived caregiver burden (Wozniak \& Izycki, 2014). In addition, Sharpe, Butow, Smith, McConnell, and Clarke (2005) asserted that caregivers often choose to refrain from communicating their needs and feelings in order to maintain the feelings of patients and other people around them. The effect of this decision is that the caregiver feels isolated and misunderstood; the caregiver prevented the possibility of receiving social support.

The tendency of the family caregiver to isolate her- or himself from the family resulted in a high caregiver burden (Rodakowski, Skidmore, Rogers, \& Schulz, 2012), and this high level of burden makes the family caregiver feel unsupported by the people around them. Insufficient 
family support increases the pressure experienced by the family caregiver (Sharpe et al., 2005). Many factors can influence the amount of pressure felt by the family caregiver. Pohan and Sukarlan (2012) found that the characteristics of the medical conditions of the patient could influence the pressure on the family caregiver. In addition, several characteristics of caregivers can increase caregiver burden, including marital status (i.e., unmarried), a young age, female sex, low education level, length of caregiving time, infrequent visits from family members, poor family functioning, low self-esteem, low monthly income, insufficient or absence of social support, physical health problems, depression, and anxiety (Kim et al., 2016). Therefore, family functioning and caregiver burden are considered to have a relationship, especially in family caregivers of patients with breast cancer. Barnes (2012) investigated the relationship between family functioning and the burden on family caregivers in a population of parents who were family caregivers for chronically ill patients (i.e., children with brain paralysis), and the results demonstrated that the higher the level of family functioning in the family of the caregiver, the lower the perceived burden level and depression.

Based on the aforementioned description, we observe a relationship between family functioning and caregiver burden. As explained, both variables can cause psychosocial dysfunction such as depression and anxiety. Disruption of communication in the family and changes in the roles played by the family caregiver also trigger high caregiver burden, but communication and roles are the dimensions of family functioning. Caregiver burden affects the family caregiver, the caregiving provided by the family caregiver, and the patient as a result of patient interaction and family caregiver as a family. In addition, families with a member who has received a breast cancer diagnosis compared with other types of cancer diagnoses (e.g., colorectal cancer) have higher levels of anxiety (Edwards \& Clarke, 2004).

According to our review of the literature, conducting research on the relationship between family functioning and caregiver burden on the family caregiver of patients with breast cancer in Indonesia would be a valuable contribution. Thus, in this study, we aim to investigate the relationship between family functioning and caregiver burden and the correlation for each family functioning dimension.

\section{Materials and Methods}

\section{A. Theoretical}

We study two variables: family functioning and caregiver burden. Family functioning is all the aspects of the family that aim to maintain and fulfill all the social, biological, and psychological aspects of the development of family member (Epstein et al., 1978). This study uses family functioning and the McMaster Model of Family Functioning (MMFF), which uses a system approach as the basis for its assumptions (Miller, Ryan, Keitner, Bishop, \& Epstein, 2000).

Thus, we base this study on the following five factors. First, the system approach has five basic assumptions, and each part of the family is related. Second, one part of the family cannot 
be understood if separated from the whole system in the family. Third, family functioning cannot be fully understood by understanding only one individual in the family. Fourth, family structure and organization is a critical factor that strongly influences and determines the behavior of each family member. Fifth, the transactional pattern of the family system is a strong factor that shapes the behavior of each family member.

From the perspective of the MMFF, family functioning has six dimensions: problem-solving, communication, regulation, affective response, affective involvement, and behavioral control (Epstein et al., 1978). First, the problem-solving dimension is defined as the family's ability to solve problems to a level that maintains a good family function. Second, the dimension of communication is defined as the process of exchanging information in verbal form between family members. Third, the role dimension in the family is defined as a repetitive pattern of individual behavior that fulfills family functions (Epstein et al., 1978). Fourth, the dimension of affective response is defined as the ability to respond to various stimuli with appropriate quality and quantity of feeling (Miller et al., 2000). Fifth, the dimension of affective engagement is defined as the extent to which the family displays interest and appreciates the activities and interests of family members. Sixth, the dimension of behavioral control is defined as a pattern applied by the family to handle behavior in three specific situations: a physically dangerous situation, a situation involving meetings and disclosure of psychobiological knowledge and encouragement, and situations involving socialization behavior inside and outside of the family (Epstein et al., 1978).

The second variable is the caregiver burden. Zarit et al., (1980) defined the caregiver burden as the extent to which caregivers feel depressed by the emotions, physical health, social life, and financial status that they feel when caring for their relatives or family members. Caregiver burden can be categorized as objective or subjective (Kim et al., 2016). The caregiver burden objective is intended to the tasks as a family caregiver (Ejem, 2014). Objective burdens can be interpreted as specific events and activities related to caregiving such as financial problems or the absence of personal activities (Wozniak \& Izycki, 2014).

Conversely, the subjective caregiver burden includes psychological factors such as sadness, guilt, fear, anxiety, and depression. The subjective level of caregiver burden experienced by the family caregiver is influenced by factors related to patients that start with the initial symptoms, including decreasing functional status, short life after diagnosis, and time period until death (Given, Sherwood, \& Given, 2011; Grunfeld et al., 2004; Kim et al., 2016).

\section{B. Instruments}

The instrument in this study uses a questionnaire in the form of self-report. Participants are asked to answer the questionnaire statement in accordance with what they feel. The questionnaire comprised informed consent sheets, participants' personal data, patient self-data, and measuring instruments. The measuring instruments we use are the Family Assessment Device (FAD), to measure family functioning, and the Zarit Burden Interview (ZBI), to measure the burden on the family caregiver of patients with breast cancer. 
The FAD was developed by Epstein, Baldwin and Bishop, in 1983, to measure the dimensions of the McMaster Model according to the perception of each family member (Epstein et al., 1983). The FAD also measures the six dimensions of the Mc-Master Model and the overall family functioning (Miller et al., 2000). The FAD comprises 60 items: Each family member is asked to rate each statement that describes the aspects of the family functioning by choosing one of four alternative responses. Individual responses are calculated using 4-point Likert scale (4 = strongly agree, $3=$ agree, 2 = disagree, and $1=$ strongly disagree) (Ryan, Epstein, Keitner, Miller \& Bishop, 2012).

The ZBI is a measurement tool commonly used to measure caregiver burden (Bachner \& O'rourke, 2007). ZBI is the longest instrument, is often used in measuring pressure from care, and has been translated into several languages that allow for international comparisons (Schreiner, Sherwood, \& Given, 2006). The ZBI comprises 22 items that measure subjective burden by using a'4-point Likert scale $(0=$ never, $1=$ rarely, $2=$ sometimes, $3=$ quite frequently, and $4=$ nearly always) Items are classified into five dimensions: burden in relationships, emotional well-being, social and family life, finance, loss of control over life (Rafiyah, Suttharangsee, \& Sangchan, 2012).

\section{Samples}

This study has a sample of 35 participants: family caregivers of patients with breast cancer who have been treated for at least 3 months. Participants have a minimum age of 18 years and live in Jakarta, Bogor, Depok, Tangerang, and Bekasi. The sampling technique of this study uses non-probability sampling. The non-probability sampling technique is used when the researcher does not know information about the amount of the intended population (Gravetter $\&$ Forzano, 2012). The type of non-probability sampling in this study is purposive sampling.

In this study, we personally approached the participants, who were in the hospital. Data collection was conducted on April 15 to May 6, 2018, by administering a questionnaire to 35 caregivers of patients with breast cancer who lived in hospitals or a shelter house. After we collected the data, we processed the data statistically using SPSS.

\section{Results}

Regarding the sample of 35 participants; $77.14 \%$ were female; $42.86 \%$ were in the middle age group (aged 41-65 years); $68.57 \%$ belonged to religions that are part of Islam; $45.71 \%$ had a high school education, which was the highest level of education attained; $60 \%$ were married; $62.5 \%$ had $0-2$ children; $40 \%$ were children of patients with breast cancer; $68.57 \%$ lived with patients; and the majority had a family of more than four members who lived together in one home. Additionally, as many as $40 \%$ of the participants who treated patients with breast cancer for more than 1 year and in addition to being a family caregiver of $60 \%$ of the participants are people who are working. The amount of expenditure per month for $40 \%$ of the participants was Rp1.500.000-3.000.000. Based on health, 74.28\% of participants felt they had a healthy body, and nine participants reported health problems, such as aches, dizziness, and fatigue. 
Furthermore, based on the data from patients with breast cancer, patients treated by the $77.14 \%$ family caregiver were in the middle-aged group (41-65 years), and all the patients were female. A total of $48.57 \%$ of the performance status held by patients is Stage 2, and the most common treatment, for $57.14 \%$ of patients, was chemotherapy. As much as $85.71 \%$ of patients did not have limitations and disabilities, and $14.28 \%$ of patients felt limitations, such as difficulty moving or walking. The highest range of cancer diagnosis years was $85.71 \%$ in the 2016-2018 range. The highest education of patients with breast cancer, by 40\%, was high school. Additionally, $80 \%$ of patients with breast cancer were married. In addition to the family caregiver, some patients with breast cancer were also receiving caregiving from other people, such as their husbands, children, or relatives. After examining the participants' demographic data, we examined at the general overview of the family functioning and the caregiver burden.

Table I. General Description Family Functioning and Caregiver Burden

\begin{tabular}{|c|c|c|c|c|c|c|}
\hline \multicolumn{2}{|l|}{ Variable } & Min & Max & $\mathbf{M}$ & SD & $\begin{array}{l}\text { Medi } \\
\text { an }\end{array}$ \\
\hline \multirow{7}{*}{$\begin{array}{l}\text { Family } \\
\text { Functioni } \\
\text { ng }\end{array}$} & Ps & 14 & 24 & 18,43 & 0,411 & 18 \\
\hline & $\mathbf{C}$ & 16 & 28 & 23,66 & 2,473 & 23 \\
\hline & $\mathbf{R}$ & 19 & 34 & 28,89 & 3,113 & 30 \\
\hline & $\mathbf{A r}$ & 11 & 21 & 15,74 & 2,160 & 16 \\
\hline & $\mathbf{A i}$ & 11 & 28 & 19,26 & 3,441 & 20 \\
\hline & Bc & 17 & 30 & 24,37 & 2,971 & 24 \\
\hline & Gf & 25 & 44 & 35,40 & 3,987 & 35 \\
\hline $\begin{array}{l}\text { Caregiver } \\
\text { Burden }\end{array}$ & & 4 & 55 & 23,71 & 12,57 & 21 \\
\hline
\end{tabular}

Based on table I, the mean score of family functioning was generally the highest level $(\mathrm{M}=$ $35.40, \mathrm{SD}=3.987$ ), and a family caregiver caring for a breast cancer patient tended to have a family functioning level above the median. The family functioning dimensions' dimensions that had an average score above the median were problem-solving $(\mathrm{M}=18.43, \mathrm{SD}=0.411)$, communication $(\mathrm{M}=23.66, \mathrm{SD}=1.473)$, roles $(\mathrm{M}=28,89, \mathrm{SD}=3.113)$, affective involvement $(\mathrm{M}=24.37, \mathrm{SD}=2.971)$, and behavior control $(\mathrm{M}=35.40, \mathrm{SD}=3.987)$. Having an average score above the median means that the average score of participants was above the middle score. In addition, some dimensions had an average score below the median in the dimension of affective responsiveness $(\mathrm{M}=15.74, \mathrm{SD}=2.160)$. This result means that the average score on the dimension of affective responsiveness was below the median score. The caregiver burden was $\mathrm{M}=23.71$ and $\mathrm{SD}=12.57$ and had an average score above the median.

Furthermore, in the examination of the family functioning relationship with the caregiver burden, we examined the relationship between the total general functioning or family functioning scores in general and the total caregiver burden score by using Pearson correlation statistical tests. The calculation results are presented in table II. 
Table II. Correlation Between Family Functioning and Caregiver Burden

\begin{tabular}{|l|l|l|}
\hline \multicolumn{3}{|c|}{ Correlation } \\
\hline & ZBI & Conclusion \\
\hline General & $-0,597$ & Significant \\
Functioning & $\mathrm{P}<0,05$ & \\
\hline
\end{tabular}

Based on the table II, we conclude that, in general, the family functioning or general functioning and caregiver burden of the family caregiver caring for a breast cancer patient has a significant negative correlation, $\mathrm{r}(35)=-0.597, \mathrm{p}<0.05$. Having a negative correlation means that the higher the value of family functioning, the lower the caregiver burden of the family caregiver caring for a breast cancer patient, and vice versa. Based on these results, the alternative hypothesis of this research is accepted and the null hypothesis is rejected. Furthermore, we observe the relationship of family functioning dimensions with the caregiver burden, which is presented in table III.

Table III. Correlation Between Family Functioning and Caregiver Burden

\begin{tabular}{|l|l|l|}
\hline \multicolumn{3}{|c|}{ Correlation } \\
\hline & ZBI & Conclusion \\
\hline \multirow{2}{*}{$\boldsymbol{s}$} & $-0,296$ & not significant \\
& $p>0,05$ & \\
\hline $\boldsymbol{C}$ & $\begin{array}{l}-0,136 \\
p>0,05\end{array}$ & not significant \\
\hline $\boldsymbol{R}$ & $-0,523$ & significant \\
& $p<0,05$ & not significant \\
\hline \multirow{2}{*}{$\boldsymbol{A} \boldsymbol{A}$} & $-0,237$ & \\
\hline \multirow{2}{*}{$\boldsymbol{i}$} & $p>0,05$ & not significant \\
\hline \multirow{2}{*}{$\boldsymbol{B} \boldsymbol{C}$} & $-0,275$ & \\
\hline & $p>0,05$ & not significant \\
\hline
\end{tabular}

Based on table III, the dimensions of family functioning that have a significant correlation with the burden caregiver are the roles of dimension. Role and caregiver burden have a significant negative correlation, $\mathrm{r}(35)=-0.523, \mathrm{p}<0.01$. Based on these results, the higher the value in the role dimension, the lower the caregiver burden for the family caregiver caring for a breast cancer patient.

\section{Discussion and Conclusion}

Family functioning and the characteristics of the diseases patients must endure are associated with psychological problems such as depression and anxiety as well as a burden on their families (Edward \& Clarke, 2004). In families managing a cancer diagnosis, families with a low level of family functioning will be at risk of having psychological problems such as burden, depression, and anxiety (Nissen et al., 2016). This statement supports the results of 
this study: We observe a significant negative correlation between family functioning and caregiver burden for the family caregivers of patients with breast cancer. A negative correlation identifies that both variables have a contradictory relationship, that is, if the family caregiver of a breast cancer patient has a high score of family functioning, the score of caregiver burden is low. The research that supports the results of this study is Barnes (2012), in a population of parents who were family caregivers for patients undergoing long-term treatment, namely, children with cerebral paralysis.

This study investigated the correlation between family functioning, family caregiver burden, and depression. The results of this study are as follows: The balance of relationships in the family and the flexibility of the family result in low levels of burden and depression for the family caregiver. That is, when the family functions properly, the burden borne by the family caregiver is reduced.

This research also examined how the family functioning dimensions correlate with the caregiver burden. Based on the results of the study, the dimensions that have a significant correlation with the burden caregiver are roles. The role dimension has a significant negative correlation with the caregiver burden, that is, the higher the score of the role, the lower the burden on the caregiver owned by the family caregiver of patients with breast cancer. The results of this study are supported by Wozniak and Izycki (201), who explained the impact of cancer on family functioning. When families manage a cancer diagnosis, major changes in the family occur, especially changes in the family members' pre-diagnosis roles. They conducted informal interviews with participants who were children who became a family caregiver for their mother.

Based on the results of the interview in this study, the participants had been caring for patients with breast cancer for more than 1 year in one of the shelter houses. One participant said the she had treated patients when she was a final year student. The participants felt very burdened by the task of being a family caregiver and being a final year student simultaneously. Participants claimed the burden of working on two things simultaneously was heavy. In addition, when graduating from college, participants delayed working and chose to caring the treatment of patients in the hospital.

In addition, as already discussed in the brief interview results, the family caregiver tends to put aside her or his work and to provide caregiving to the patients with breast cancer. The description of these two participants presented the results of the study, namely, the change or the extended roles that have been causing the burden on the participants. In addition, the condition of the participant was also in accordance with Wozniak and Izycki (2014): Cancer causes family members of patients to delay future plans. This phenomenon can be observed in the decision of the participants not to work and focus on the caring of and the treatment for patients.

In addition, the main results of other dimensions such as problem-solving, communication, affective responsiveness, affective involvement, and behavior control do not have a significant 
correlation to the caregiver burden of the family caregiver; based on these results, we observed that this could be caused by the characteristics and conditions of the family caregiver at this time. In the problem-solving dimension, we assumed that in managing cancer, the family caregiver tended to trust all medications, doctors, and hospitals. This assumption was deduced from the results of informal interviews when the data were collected. Participants said that cancer treatment for patients depends on only the hospital. In addition, the high cost of cancer treatment makes participants very dependent on the use of BPJS Kesehatan. This result is also supported by a discussion on Toseland, Blanchard, and McCallion (1995), which said that the problems managed by a family caregiver regarding caregiving for patients with cancer did not cause the family caregiver to be too stressed or depressed; however, the caregiver felt relatively effective at overcoming cancer problems. Therefore, we conclude that the problemsolving dimension is very much influenced by many factors, especially in the family caregiver population of patients with breast cancer.

Similar to the problem-solving dimension, in other dimensions, communication, affective responsiveness, affective involvement, and behavior control also do not have a significant correlation with the caregiver burden in the population of family cancer caregivers. For this reason, we also suspect that it can be caused by the characteristics and conditions of the participants in this study. As many as 28 family caregivers, at the time of data collection, were staying at a shelter house near the hospital. This result means only seven people resided with other family members in their home. According to Epstein, Bishop and Levin (1978), family functioning has the assumptions that every part of the family relates to one another and one part of the family cannot be understood if it is removed from the whole system in the family. That is, to observe how the family functioning of individuals should be considered when individuals reside with other family members so that interaction is created in accordance with the dimensions of the family functioning. This is in contrast with the current condition of the participants because most participants leave other family members and only stay with patients at a shelter or rented house to facilitate the treatment process. As a result, the family caregiver does not have sufficient time to interact with other family members.

The limitation of this study is that most family caregivers of patients with breast cancer were not living with other family members because they had to undergo treatment at the hospital. The participants had to leave other family members and stay in a shelter house for an undetermined duration. As a result, some of the items from the family functioning measurement tool were not felt according to the conditions experienced by the family caregivers. Family functioning items were also difficult to understand for some participants: The participants had difficulties understanding items on the measuring instrument and communicating their self-perceptions regarding these items.

\section{Acknowledgement}

The authors would like to thank all the participants in this study. We would also like to thank the hospital and the shelter house administrators for giving permission and giving more 
information regarding breast cancer and family caregivers. A special thank you goes to Mrs. Siti for introducing us to other family caregivers.

\section{References}

Arai, Y., Hosokawa, T., Washio, M., Miura, H., \& Hisamichi, S. (1997). Reliability and validity of the Japanese version of the Zarit Caregiver Burden Interview. Psychiatry and clinical neurosciences, 51(5), 281-287

Bachner, Y. G., \& O'rourke, N. (2007). Reliability generalization of responses by care providers to the Zarit Burden Interview. Aging \& Mental Health, 11(6), 678-685.

Barnes, J. A. (2012). Family functioning, caregiver strain, and depression in parents of children with cerebral palsy (Doctoral dissertation). Trevecca Nazarene University, Tennessee.

Blanchard, C. G., Albrecht, T. L., \& Ruckdeschel, J. C. (1997). The crisis of cancer: psychological impact on family caregivers. Oncology-Huntington, 11(2), 189-195.

Cassileth, B. R., Lusk, E. J., Brown, L. L., \& Cross, P. A. (1986). Psychosocial status of cancer patients and next of kin: Normative data from the Profile of Mood States. Journal of Psychosocial Oncology, 3(3), 99-105.

Departemen Kesehatan Republik Indonesia. (2016). Indodatin Bulan Peduli Kanker Payudara. Retrieved from http://www.depkes.go.id/download.php?file=download/pusdatin/infodatin/InfoDatin\%20Bulan\%20Pedul i\%20Kanker\%20Payudara_2016.pdf.

Dorros, S. M., Card, N. A., Segrin, C., \& Badger, T. A. (2010). Interdependence in women with breast cancer and their partners: An interindividual model of distres. Journal of Consulting and Clinical Psychology, 78(1), 121-125. http://dx.doi.org/10.1037/a0017724

Edwards, B., \& Clarke, V. (2004). The psychological impact of a cancer diagnosis on families: the influence of family functioning and patients' illness characteristics on depression and anxiety. PsychoOncology, 13(8), 562-576.

Efendi, F. (2009). Keperawatan Kesehatan Komunitas: Teori dan praktik dalam keperawatan.

Effendy, C., Vernooij-Dassen, M., Setiyarini, S., Kristanti, M. S., Tejawinata, S., Vissers, K., \& Engels, Y. (2015). Family caregivers' involvement in caring for a hospitalized patient with cancer and their quality of life in a country with strong family bonds. Psycho- Oncology, 24(5), 585-591.

Ejem, D. B. (2014). The Effects of Subjective and Objective Caregiver Burden on the Depressive Symptomology of a Disabled Older Adult Care Recipient (Doctoral dissertation). University of Alabama, Birmingham.

Epstein, N. B., Baldwin, L. M., \& Bishop, D. S. (1983). The McMaster family assessment device. Journal of marital and family therapy, 9(2), 171-180.

Epstein, N. B., Bishop, D. S., \& Levin, S. (1978). The McMaster model of family functioning. Journal of Marital and Family therapy, 4(4), 19-31.

Friedman, L. C., Baer, P. E., Nelson, D. V., Lane, M., Smith, F. E., \& Dworkin, R. J. (1988). Women with breast cancer: perception of family functioning and adjustment to illness. Psychosomatic Medicine, 50(5), 529-540.

Fujinami, R., Sun, V., Zachariah, F., Uman, G., Grant, M., \& Ferrell, B. (2015). Family caregivers' distres levels related to quality of life, burden, and preparedness. Psycho- Oncology, 24(1), 54-62.

Ginayarahmah, S. (2013). Caregiver Strain Pada Caregiver Informal yang Merawat Pengidap Penyakit Kronis (Unpublished undergraduate mini thesis). Universitas Indonesia, Depok, Indonesia.

Given, B. A., Sherwood, P., \& Given, C. W. (2011). Support for caregivers of cancer patients: transition after active treatment. Cancer Epidemiology and Prevention Biomarkers, 20(10), 2015-2021.

Given, B. A., Given, C. W., \& Sherwood, P. (2012). The challenge of quality cancer care for family caregivers. In Seminars in oncology nursing (Vol. 28, No. 4, pp. 205-212). WB Saunders.

Goldstein, N. E., Concato, J., Fried, T. R., \& Kasl, S. V. (2004). Factors associated with caregiver burden among caregivers of terminally ill patients with cancer. Journal of palliative care, 20(1), 38.

Gravetter, F., \& Forzano, L. (2012). Research methods for the behavioral sciences (4th ed.). Belmont, CA: Wadsworth Cengage Learning. 
Grunfeld, E., Coyle, D., Whelan, T., Clinch, J., Reyno, L., Earle, C. C., ... \& Glossop, R. (2004). Family caregiver burden: results of a longitudinal study of breast cancer patients and their principal caregivers. Canadian Medical Association Journal, 170(12), 1795-1801.

Kershaw, T., Northouse, L., Kritpracha, C., Schafenacker, A., \& Mood, D. (2004). Coping strategies and quality of life in women with advanced breast cancer and their family caregivers. Psychology \& Health, 19(2), 139-155.

Kim, H. H., Kim, S. Y., Kim, J. M., Kim, S. W., Shin, I. S., Shim, H. J., Hwang, J. E., Chung, I. J., \& Yoon, J. S., (2016). Influence of caregiver personality on the burden of family caregivers of terminally ill cancer patients. Palliative \& supportive care, 14(1), 5-12.

Miller, I. W., Ryan, C. E., Keitner, G. I., Bishop, D. S., \& Epstein, N. B. (2000). The McMaster approach to families: Theory, assessment, treatment and research. Journal of Family Therapy, 22(2), 168-189.

Navaie-Waliser, M., Spriggs, A., \& Feldman, P. H. (2002). Informal caregiving: differential experiences by gender. Medical care, 40(12), 1249-1259.

Nijboer, C., Tempelaar, R., Sanderman, R., Triemstra, M., Spruijt, R. J., \& Van Den Bos, G. A. (1998). Cancer and caregiving: the impact on the caregiver's health. Psycho oncology, 7(1), 3-13.

Nissen, K. G., Trevino, K., Lange, T., \& Prigerson, H. G. (2016). Family Relationships and Psychosocial Dysfunction Among Family Caregivers of Patients with Advanced Cancer. Journal of Pain and Symptom Management, 52(6), 841-849.

Pohan, L. D \& Sukarlan, A.D.P (2012). Family caregivers of people with medical conditions that require-long term care. Proceedings Southeast Asia Psychology Conference. Kota Kinabalu, Malaysia: Universiti Malaysia Sabah

Rafiyah, I., Suttharangsee, W., \& Sangchan, H. (2012). Coping and Burden of Indonesian Family Caregivers Caring for Persons with Schizophrenia. Songklanagarind Medical Journal, 30(3), 135-142.

Rodakowski, J., Skidmore, E. R., Rogers, J. C., \& Schulz, R. (2012). Role of social support in predicting caregiver burden. Archives of physical medicine and rehabilitation, 93(12), 2229-2236.

Ryan, C. E., Epstein, N. B., Keitner, G. I., Miller, I. W., \& Bishop, D. S. (2012). Evaluating and treating families: The McMaster approach. New York: Routledge.

Schreiner, A. S., Morimoto, T., Arai, Y., \& Zarit, S. (2006). Assessing family caregiver's mental health using a statistically derived cut-off score for the Zarit Burden Interview. Aging and Mental Health, 10(2), 107111.

Schuler, T. A., Zaider, T. I., Li, Y., Hichenberg, S., Masterson, M., \& Kissane, D. W. (2014). Typology of perceived family functioning in an American sample of patients with advanced cancer. Journal of pain and symptom management, 48(2), 281-288.

Sharpe, L., Butow, P., Smith, C., McConnell, D., \& Clarke, S. (2005). The relationship between available support, unmet needs and caregiver burden in patients with advanced cancer and their careers. PsychoOncology, 14(2), 102-114.

Tavassoli, F. A., \& Devilee, P. (2003). Pathology and genetics of tumours of the breast and female genital organs. Lyon: International Agency for Research on Cancer (IARC)

Toseland, R. W., Blanchard, C. G., \& McCallion, P. (1995). A problem-solving intervention for caregivers of cancer patients. Social Science \& Medicine, 40(4), 517-528.

Weaver, A. J., \& Flannelly, K. J. (2004). The role of religion/spirituality for cancer patients and their caregivers. Southern Medical Journal, 97(12), 1210-1214.

Weitzner, M. A., McMillan, S. C., \& Jacobsen, P. B. (1999). Family caregiver quality of life: differences between curative and palliative cancer treatment settings. Journal of pain and symptom management, 17(6), 418-428.

World Health Organization. (2015). Cancer. Retrieved from http://www.who.int/en/news-room/factsheets/detail/cancer.

Wozniak, K., \& Izycki, D. (2014). Cancer: A family at risk. Przeglad Menopauzalny, 13(4), 253-261. http://dx.doi.org/10.5114/pm.2014.45002

Zarit, S. H., Reever, K. E., \& Bach-Peterson, J. (1980). Relatives of the impaired elderly: correlates of feelings of burden. The gerontologist, 20(6), 649-655. 